\title{
Compactação do solo na cultura do arroz de terras altas(1)
}

\author{
Cleber Morais Guimarães ${ }^{(2)}$ e José Aloísio Alves Moreira ${ }^{(2)}$
}

\begin{abstract}
Resumo - A presente pesquisa teve o objetivo de avaliar o efeito da compactação do solo sobre duas cultivares de arroz de terras altas. O experimento foi realizado em casa de vegetação, utilizando um Latossolo Vermelho-Escuro, de textura franca, com densidades do solo de 1,2, 1,3, 1,4, 1,5, 1,6 e $1,7 \mathrm{~g} \mathrm{~cm}^{-3}$. Estas densidades foram produzidas artificialmente, na camada de $0-20 \mathrm{~cm}$ de profundidade, em colunas de solo com $24,4 \mathrm{~cm}$ de diâmetro. O solo foi mantido em potencial da água superior a $-0,035 \mathrm{MPa}$. O comportamento do arroz foi avaliado aos 40 dias após a emergência, por meio de parâmetros da parte aérea e radicular da planta. O crescimento da parte aérea do arroz de terras altas diminui com o aumento da densidade do solo a partir de $1,2 \mathrm{~g} \mathrm{~cm}^{-3}$; as raízes na camada compactada de 0-20 cm de profundidade apresentam engrossamento, em razão do aumento da densidade do solo; e a compactação superficial do solo diminui a quantidade de raízes presentes nesta camada e na camada inferior não-compactada de 20-40 cm de profundidade.
\end{abstract}

Termos para indexação: Oryza sativa, sistema radicular, partes aéreas, densidade do solo

\section{Soil compaction on upland rice}

\begin{abstract}
A greenhouse experiment was conducted with the objective to evaluate the effects of soil compaction on two upland rice genotypes grown in a Dark Red Latosol with loam texture, having densities of $1.2,1.3,1.4,1.5,1.6$ and $1.7 \mathrm{~g} \mathrm{~cm}^{-3}$. Soil density values were created artificially at $0-20 \mathrm{~cm}$ soil depth using plastic tubes of $24.4 \mathrm{~cm}$ of diameter. Soil water potential was maintained at $-0.035 \mathrm{MPa}$. Treatment effects were evaluated 40 days after seedling emergence using the shoot dry weight and the root system as parameters. Results obtained for both cultivars indicated that shoot growth was decreased by increasing soil density beyond $1.2 \mathrm{~g} \mathrm{~cm}^{-3}$ and also that root thickness increased with increasing soil density. Additionally, superficial soil compaction reduced the amount of roots present at $0-20 \mathrm{~cm}$ soil depth as well as at $20-40 \mathrm{~cm}$.
\end{abstract}

Index terms: Oryza sativa, root systems, aerial parts, soil density.

\section{Introdução}

As raízes das plantas ao se desenvolverem no solo atravessam poros com diâmetros superiores aos seus, ou outros poros que foram aumentados pelo deslocamento das partículas do solo através do seu crescimento, o qual será diminuído ou inexistente quando a pressão hidrostática das células das raízes não for capaz de vencer a resistência oferecida pelas camadas de compactação dos solos (Taylor, 1974).

(1) Aceito para publicação em 25 de julho de 2000.

(2) Embrapa-Centro Nacional de Pesquisa de Arroz e Feijão, Caixa Postal 179, CEP 75375-000 Santo Antônio de Goiás, GO

E-mail: cleber@cnpaf.embrapa.br, jaloisio@cnpaf.embrapa.br
As plantas desenvolvem-se melhor em solos que não apresentam limitação ao crescimento radicular, portanto com baixa densidade, porém alta o suficiente para oferecer bom contato raízes-partículas de solo (Seguy et al., 1984; Avidsson \& Hakansson, 1991; Stirzaker et al., 1996; Kluthcouski, 1998). Em solos muito compactados, pode ocorrer rapidamente a depleção de água e de nutrientes disponíveis ao sistema radicular que explora um pequeno volume de solo. Por outro lado, em solos com baixos valores de densidade, o crescimento deficiente de plantas pode ser devido à menor absorção de nutrientes em conseqüência do baixo contato solo-raízes (Stirzaker et al., 1996). Conseqüentemente, a absorção de água e nutrientes será tanto maior quanto maior a quantidade de raízes presentes em ambientes com maior disponibilidade de nutrientes e quanto melhor 
for o contato raízes-partículas do solo. A compactação do solo que limitar a taxa de alongamento radicular, ou não permitir bom contato raízes-partículas, ao reduzir o desenvolvimento das plantas, geralmente o faz também com relação à produtividade (Veen et al., 1992).

A movimentação de máquinas agrícolas pode ocasionar compactação superficial dos solos, que, ao limitar o desenvolvimento radicular, compromete o crescimento e a produtividade das plantas quando estas dependem somente da chuva para suprir suas necessidades, principalmente quando ocorre precipitação pluvial irregular. Em tais condições, as plantas esgotam rapidamente as reservas hídricas disponíveis no solo, podendo ocorrer severa deficiência hídrica na planta (Barton et al., 1966).

A compactação do solo pode ser avaliada pela sua densidade, que pode atingir níveis críticos na camada superficial no sistema plantio direto.

O objetivo deste trabalho foi estudar o efeito de diversas densidades do solo sobre o desenvolvimento do arroz de terras altas.

\section{Material e Métodos}

O estudo foi realizado em casa de vegetação na Embrapa-Centro Nacional de Pesquisa de Arroz e Feijão, em Santo Antônio de Goiás, GO. O solo utilizado foi um Latossolo Vermelho-Escuro, franco, com as seguintes características químicas e físicas: $\mathrm{pH}\left(\mathrm{H}_{2} \mathrm{O}\right) 5,9$; $\mathrm{Ca}^{2+}$, $15 \mathrm{mmol}_{\mathrm{c}} \mathrm{dm}^{-3} ; \mathrm{Mg}^{2+}, 10 \mathrm{mmol}_{\mathrm{c}} \mathrm{dm}^{-3} ; \mathrm{Al}, 1 \mathrm{mmol}_{\mathrm{c}} \mathrm{dm}^{-3}$. $\mathrm{P}, 2,4 \mathrm{mg} \mathrm{dm}^{-3} ; \mathrm{K}, 51 \mathrm{mg} \mathrm{dm}^{-3} ; \mathrm{Cu}, 16 \mathrm{mg} \mathrm{dm}^{-3} ; \mathrm{Zn}$, $2,4 \mathrm{mg} \mathrm{dm}^{-3}$; Fe, $176 \mathrm{mg} \mathrm{dm}^{-3}$; Mn, $11 \mathrm{mg} \mathrm{dm}^{-3}$; M.O., $19 \mathrm{~g} \mathrm{~kg}^{-1}$; silte, $315 \mathrm{~g} \mathrm{~kg}^{-1}$; areia, $480 \mathrm{~g} \mathrm{~kg}^{-1} \mathrm{e}$ argila, $225 \mathrm{~g} \mathrm{~kg}^{-1}$, determinadas segundo método da Embrapa (1979). Utilizou-se o delineamento experimental em blocos ao acaso, com parcelas subdivididas, e três repetições. As unidades experimentais foram colunas de solo, acondicionadas em tubos de PVC de $24,4 \mathrm{~cm}$ de diâmetro e $40 \mathrm{~cm}$ de altura, onde foram colocadas cinco sementes das cultivares Caiapó e CIRAD L-141. Após a emergência, fezse o desbaste, deixando três plântulas por coluna de solo. As plantas de arroz constituíram as parcelas, e as densidades do solo, 1,2, 1,3, 1,4, 1,5, 1,6 e 1,7 $\mathrm{g} \mathrm{cm}^{-3}$ constituíram as subparcelas. As densidades de solo foram produzidas artificialmente na camada de $0-20 \mathrm{~cm}$ de profundidade com o auxílio de uma prensa hidráulica. Na camada de $20-40 \mathrm{~cm}$ de profundidade, a densidade foi mantida a $1,2 \mathrm{~g} \mathrm{~cm}^{-3}$. O solo usado foi secado ao ar e passado em peneiras com malha de $2 \mathrm{~mm}$. Durante a execução do experimento, as irrigações foram feitas mantendo-se sempre o solo a um potencial de água superior a $-0,035 \mathrm{MPa}$. A densidade de comprimento radicular e massa seca de raízes foram determinados 40 dias após a emergência das plântulas nas camadas de $0-20 \mathrm{~cm}$ e de $20-40 \mathrm{~cm}$ de profundidade. A separação das raízes presentes nas amostras de solo foi feita por meio do método de suspensão/decantação repetitivas. Após a separação, as raízes foram recuperadas do sobrenadante em peneiras de $0,25 \mathrm{~mm}$, com o auxílio de pinças. A seguir, as raízes foram avaliadas quantitativamente pelo método de Newman (1966), para determinar o comprimento total das raízes na amostra de solo. Dividindo-se o comprimento radicular $(\mathrm{cm})$ pelo volume das amostras $\left(\mathrm{cm}^{3}\right)$, encontrou-se a densidade de comprimento radicular (Proffitt et al., 1985; Taylor, 1986). Após a determinação da densidade de comprimento radicular, as raízes, juntamente com as plantas de arroz coletadas na mesma ocasião, foram secadas em estufa com circulação forçada de ar a $80^{\circ} \mathrm{C}$, durante 48 horas, para determinação de suas respectivas massas secas. A espessura radicular foi determinada pela relação massa seca radicular $(\mathrm{mg}) /$ comprimento radicular $(\mathrm{cm})$, conforme Oussible et al. (1992), e a relação parte aérea/sistema radicular, por meio da massa seca da parte aérea total $(\mathrm{g}) /$ massa seca das raízes $(\mathrm{g})$

\section{Resultados e Discussão}

A cultivar Caiapó, ao produzir 10,74 g/coluna de massa seca da parte aérea, foi $18,8 \%$ mais produtiva que a CIRAD L-141, porém ambas responderam com a mesma intensidade aos efeitos dos aumentos das densidades do solo (Tabela 1). Por outro lado, além de apresentarem, na camada compactada de $0-20 \mathrm{~cm}$ de profundidade, densidades médias de comprimento radicular semelhantes, de 5,21 e $5,08 \mathrm{~cm} \mathrm{~cm}^{-3}$. respectivamente, essas cultivares responderam também com a mesma intensidade aos efeitos das densidades do solo (Tabela 1). Por esse motivo, serão discutidas apenas suas médias.

A massa seca da parte aérea foi reduzida com o aumento da densidade do solo. A relação descrita pelas variáveis foi exponencial e inversa (Figura 1). Observou-se que a quantidade de massa seca da parte aérea sofreu redução de $35,8 \%$, em conseqüência do aumento de $0,5 \mathrm{~g} \mathrm{~cm}^{-3}$ da densidade do solo, entre os 1,2 e 1,7 $\mathrm{g} \mathrm{cm}^{-3}$, ou seja uma redução média de $7,16 \%$ a cada $0,1 \mathrm{~g} \mathrm{~cm}^{-3}$ de aumento na densidade 
do solo. Este resultado foi similar aos observados por Rosolem et al. (1994) e Fernandez et al. (1995), com a cultura da soja. Atwell (1990) atribuiu o menor crescimento das plantas de trigo em condições de compactação de solo à menor absorção dos nutrientes mais lixiviáveis, como $\mathrm{Ne} \mathrm{K}$, visto que o sistema radicular presente na camada superficial do solo supriu adequadamente a planta com $P$.

A densidade de comprimento radicular, nas camadas do solo de 0-20 e 20-40 cm de profundidade, foi também afetada pela compactação do solo. A redução da densidade de comprimento radicular foi maior na camada de 20-40 cm (Figura 2). Foram observados $6,73 \mathrm{~cm} \mathrm{~cm}^{-3}$ na densidade do solo de $1,2 \mathrm{~g} \mathrm{~cm}^{-3}$, e $0,98 \mathrm{~cm} \mathrm{~cm}^{-3}$ na densidade de $1,7 \mathrm{~g} \mathrm{~cm}^{-3}$, portanto uma redução total de $85,4 \%$ do sistema radicular, ao passo que a redução da densidade de

Tabela 1. Análise da variância para a produtividade de massa seca da parte aérea e a densidade de comprimento radicular.

\begin{tabular}{lcc}
\hline Fonte de variação & \multicolumn{2}{c}{ Quadrado médio } \\
\cline { 2 - 3 } & $\begin{array}{c}\text { Massa seca } \\
\text { parte aérea } \\
\text { (g/coluna) }\end{array}$ & $\begin{array}{c}\text { Densidade de } \\
\text { comprimento } \\
\text { radicular }\left(\mathrm{cm} \mathrm{cm}^{-3}\right)\end{array}$ \\
\hline Cultivares (Caiapó x CIRAD L-141) & $25,874^{* * *}$ & 0,170 \\
Densidade do solo & $19,857^{* * *}$ & $6,930^{* * *}$ \\
Cultivares x densidade do solo & $2,192^{\text {ns }}$ & $0,432^{\text {ns }}$ \\
\hline CV $(\%)$ & 12,02 & 14,92 \\
\hline
\end{tabular}

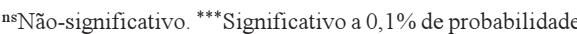

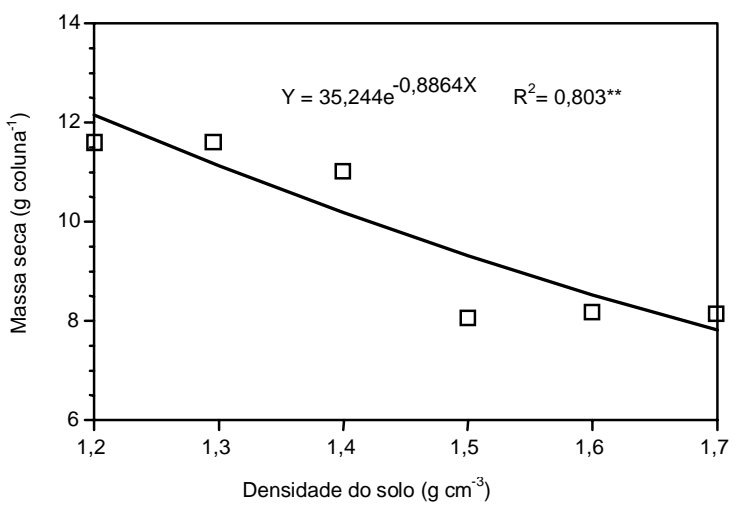

Figura 1. Massa seca da parte aérea de plantas de arroz, aos 40 dias após a emergência, cultivadas em solo com diferentes densidades na camada de $0-20 \mathrm{~cm}$ de profundidade. comprimento radicular presente na camada compactada $(0-20 \mathrm{~cm})$ foi $41,2 \%$ (Figura 2 ).

Os resultados sugerem que o sistema radicular do arroz é muito sensível à compactação do solo, diminuindo seu crescimento com o aumento da densidade de solo, a partir de $1,2 \mathrm{~g} \mathrm{~cm}^{-3}$. Resultados similares foram observados por Rosolem et al. (1994) e Fernandez et al. (1995). Conforme Atwell (1990), o crescimento das raízes seminais é, também, muito sensível à compactação do solo. Este autor verificou crescimento de raízes de trigo de 0,6 e $1,78 \mathrm{~cm} \mathrm{dia}^{-1}$, em solo compactado e descompactado, respectivamente. Por outro lado, Grohmann \& Queiroz Neto (1966) observaram uma total inibição do crescimento radicular de plântulas de arroz nas densidades do solo superiores a $1,38 \mathrm{~g} \mathrm{~cm}^{-3}$.

A relação da massa seca, entre parte aérea e as raízes das plantas, observada na camada de 0-20 cm, não foi sensível ao aumento da densidade do solo, como também observaram Rosolem et al. (1994) (Figura 3). Isto deve-se ao efeito semelhante exercido pela densidade do solo sobre a massa seca da parte aérea e das raízes de $0-20 \mathrm{~cm}$. Observou-se, no entanto, uma relação direta e exponencial com o aumento da densidade do solo, quando se consideraram as raízes presentes na camada de $20-40 \mathrm{~cm}$ de profundidade. A relação é explicada pelos maiores decréscimos do sistema radicular, nesta camada, sob o efeito da densidade do solo (Figura 2).

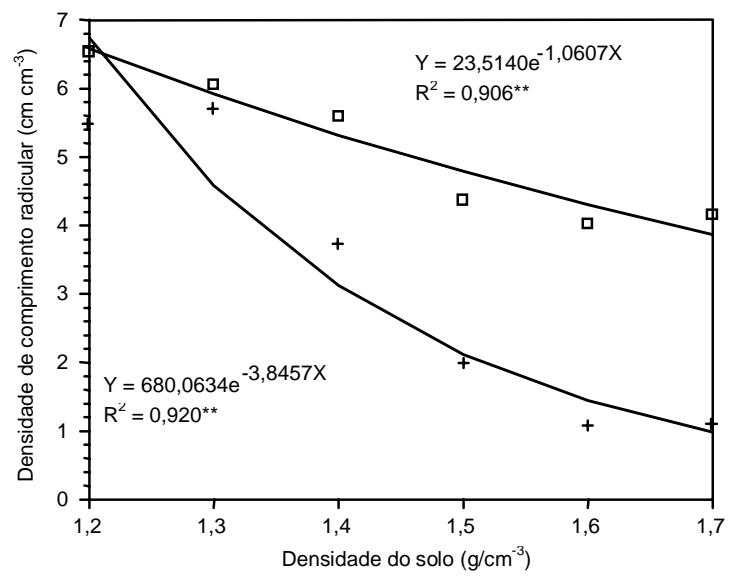

Figura 2. Densidade de comprimento radicular nas camadas do solo de 0-20 cm (口) e 20-40 cm (+) de profundidade, de plantas de arroz, aos 40 dias após a emergência, cultivadas em solo com diferentes densidades. 
A limitação ao crescimento radicular exercido pela compactação do solo causa o engrossamento das raízes (Borges et al., 1988; Oussible et al., 1992; Fernandez et al., 1995) resultante, naturalmente, do acúmulo de carboidratos. Esta variável foi inferida pela avaliação da relação massa seca radicular/comprimento radicular (Oussible et al., 1992). Observase, na Figura 4, que essa relação foi direta e exponencial na camada de $0-20 \mathrm{~cm}$ de profundidade, onde foram instalados os tratamentos de densidades do solo, enquanto na camada imediatamente abaixo, de

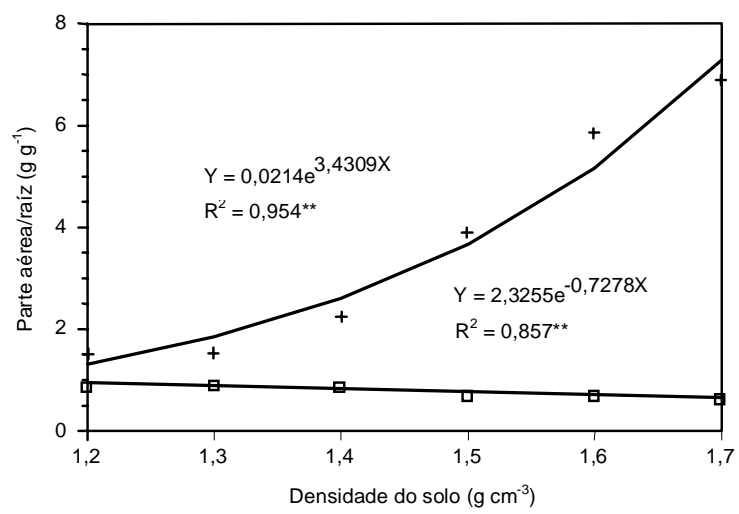

Figura 3. Relação massa seca da parte aérea/massa seca das raízes provenientes das camadas do solo de 0-20 (口) e 20-40 cm (+) de profundidade, de plantas de arroz, aos 40 dias após a emergência, cultivadas em solo com diferentes densidades na camada de 0-20 $\mathrm{cm}$ de profundidade

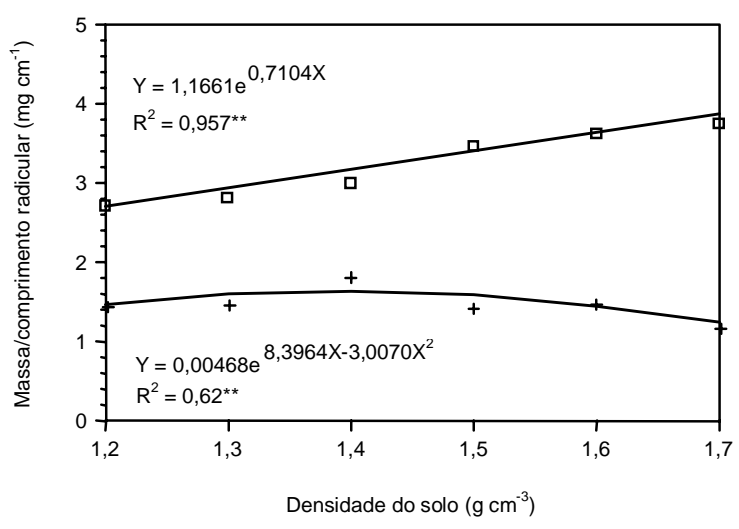

Figura 4. Relação massa seca radicular/comprimento radicular provenientes das camadas do solo de 0-20 (ם) e 20-40 cm (+) de profundidade, de plantas de arroz, aos 40 dias após a emergência, cultivadas em solo com diferentes densidades de 0-20 $\mathrm{cm}$ de profundidade
20-40 cm de profundidade, não compactada, as raízes apresentaram desenvolvimento similar entre si, independentemente do nível de compactação da camada superior. Os resultados sugerem que a compactação da camada superficial do solo causa o engrossamento e a redução da quantidade de raízes nessa camada. Causa também redução da quantidade de raízes nas camadas mais profundas do solo, porém com aspecto morfológico (espessura) semelhante ao daquelas que não foram submetidas ao estresse físico induzido pela compactação do solo.

\section{Conclusões}

1. O crescimento da parte aérea do arroz de terras altas é diminuído com o aumento da densidade do solo.

2. As raízes na camada compactada $(0-20 \mathrm{~cm})$ apresentam engrossamento em função do aumento da densidade do solo.

3. A compactação do solo na camada superficial diminui a quantidade de raízes presentes nesta camada e na camada inferior não compactada.

\section{Referências}

ATWELL, B. J. The effect of soil compaction on wheat during early tillering. New Phytologist, Cambridge, Grã-Bretanha, v. 115, p. 29-35, 1990.

AVIDSSON, J.; HAKANSSON, I. A model for estimating crop yield losses caused by compaction. Soil and Tillage Research, Amsterdam, v. 20, p. 319-332, 1991.

BARTON, H.; McCULLY, W. G.; TAYLOR, H. M.; BOX, J. E. J. Influence of soil compaction on emergence and firstyear growth of seeded grasses. Journal of Range Management, Denver, v. 19, p. 118-121, 1966.

BORGES, E. N.; NOVAIS, R. F. de; REGAZZI, A. J.; FERNANDES, B.; BARROS, N. F. de. Respostas de variedades de soja à compactação de camadas de solo. Revista Ceres, Viçosa, v. 35, n. 202, p. 553-568, 1988.

EMBRAPA. Serviço Nacional de Levantamento e Conservação de Solos (Rio de Janeiro, RJ). Manual de métodos de análises de solo. Rio de Janeiro, 1979. $1 \mathrm{v}$.

FERNANDEZ, E. M.; CRUSCIOL, C. A. C.; THIMOTEO, C. M. de S.; ROSOLEM, C. A. Matéria seca e nutrição da soja em razão da compactação do solo e adu- 
bação fosfatada. Científica, São Paulo, v. 23, n. 1, p. 117 132,1995

GROHMANN, F.; QUEIROZ NETO, J. P. de. Efeito da compactação artificial de dois solos limo-argilosos sobre a penetração das raízes de arroz. Bragantia, Campinas, v. 25, n. 38, p. $421-431,1966$.

KLUTHCOUSKI, J. Efeito de manejo em alguns atributos de um Latossolo Roxo sob cerrado e nas características produtivas de milho, soja, arroz e feijão após oito anos de plantio direto. Piracicaba : ESALQ, 1998. 179 p. Tese de Doutorado.

NEWMAN, E. L. A method of estimating the total length of root in a sample. Journal of Applied Ecology, Oxford, v. 3, p. 139-145, 1966.

OUSSIBLE, M.; CROOKSTON, R. K.; LARSON, W. E. Subsurface compaction reduces the root and shoot growth and grain yield of wheat. Agronomy Journal, Madison, v. 84 , p. $34-38,1992$.

PROFFITT, A. P. B.; BERLINER, P. B.; OOSTERHUIS, D. M. A comparative study of root distribution and water extraction efficiency by wheat grown under high and lowfrequency irrigation. Agronomy Journal, Madison, v. 77, n. 5, p. 655-662, 1985.

ROSOLEM, C. A.; ALMEIDA, A. C. da S.; SACRAMENTO, L. V. S. do. Sistema radicular e nutrição da soja em fun- ção da compactação do solo. Bragantia, Campinas, v. 53 , n. 2, p. 259-266, 1994.

SEGUY, L.; KLUTHCOUSKI, J.; SILVA, J. G. da; BLUMENSCHEIN, F. N.; DALL'ACQUA, F. M. Técnicas de preparo do solo: efeitos na fertilidade e na conservação do solo, nas ervas daninhas e na conservação de água. Goiânia : Embrapa-CNPAF, 1984. 26 p. (EmbrapaCNPAF. Circular Técnica, 17).

STIRZAKER, R. J.; PASSIOURA, J. B.; WILMS, Y. Soil structure and plant growth: impact of bulk density and biopores. Plant and Soil, Dordrecht, v. 185, p. 151-162, 1996.

TAYLOR, H. M. Methods of studying root systems in the field. HortScience, Alexandria, v. 21, n. 4, p. 952-956, 1986.

TAYLOR, H. M. Root behavior as affected by soil structure and strength. In: CARSON, E. W. (Ed.). The plant root and its environment. Charlottesville : University Press of Virginia, 1974. p. 271-291

VEEN, B. W.; NOORDWIIJK, M. van; WILIGEN, P. de; BOONE, F. R.; KOOISTRA, M. J. Root-soil contact of maize, as measured by a thin-section technique. III. Effects on shoot growth, nitrate and water uptake efficiency. Plant and Soil, Dordrecht, v. 139, n. 1, p. 131-138, 1992. 